\title{
WORK ABILITY OF EMPLOYEES IN CHANGING SOCIAL SERVICES AND HEALTH CARE ORGANIZATIONS IN FINLAND
}

\author{
LAURI KOKKINEN ${ }^{1}$ and ANNE KONU ${ }^{2}$ \\ ${ }^{1}$ Finnish Institute of Occupational Health, Turku, Finland \\ Centre of Expertise for Work Organizations \\ ${ }^{2}$ University of Tampere, Tampere, Finland \\ School of Health Sciences
}

\begin{abstract}
Objectives: In this study, we examined the connection between organizational changes and employees own evaluations of their work ability. Materials and Methods: In early 2010, we asked employees $(n=2429)$ working in the Finnish social services and health care industry to identify all the organizational changes that had occurred at their workplaces over the previous two years, and to evaluate their own work ability and whether different statements related to the elements of work ability were true or false at the time of the survey. For our method of analysis, we used logistical regression analysis. Results: In models adjusted for gender, age, marital status, professional education and managerial position, the respondents who had encountered organizational changes were at a higher risk of feeling that their work ability had decreased $(\mathrm{OR}=1.49)$ than the respondents whose workplaces had not been affected by changes. Those respondents who had encountered organizational changes were also at a higher risk of feeling that several elements related to work ability had deteriorated. The risk of having decreased self-evaluated work ability was in turn higher among the respondents who stated they could not understand the changes than among those respondents who understood the changes $(\mathrm{OR}=1.99)$. This was also the case among respondents who felt that their opportunities to be involved in the changes had been poor in comparison to those who felt that they had had good opportunities to be involved in the process $(\mathrm{OR}=2.16)$. Conclusions: Our findings suggest that the organizational changes in social and health care may entail, especially when poorly executed, costs to which little attention has been paid until now. When implementing organizational changes, it is vital to ensure that the employees understand why the changes are being made, and that they are given the opportunity to take part in the implementation of these changes.
\end{abstract}

Key words:

Organizational change, Work ability, Social services, Health care

\section{INTRODUCTION}

The Finnish social and health care system was created mainly during the 1960s and 1970s, and its institutional structure has remained relatively unaltered until today. On the level of individual organizations, however, there have been rapid changes for quite some time now. Both the service production structures and the organization of labor have been under constant development. On the organizational level, the changes implemented over the last few years have been either comprehensive and covered all activities, or have been differentiated and project-like in nature, or indeed anything between the two. The previous research literature shows evidence that certain radical changes, personnel cuts and privatization for instance, are connected to work

Received: November 12, 2011. Accepted: January 2, 2012.

Address reprint request to L. Kokkinen, Finnish Institute of Occupational Health, Lemminkäisenkatu 14-18, 20520 Turku, Finland (e-mail: lauri.kokkinen@uta.fi). 
motivation and health of employees [1-4]. However, until now, there have been few studies on how organizational changes are connected to employees' experiences when the changes involved are not brought about by a crisis situation or are not otherwise radical in nature.

In this paper, we endeavor to take into account all the organizational changes that employees of the Finnish social and health care industry have encountered at their workplaces. Unlike most previous research on organizational change and employees' experiences, ours is not only focused on the connection between the change and employees' health or motivation. Firstly, we are interested in finding out whether employees feel they are able to cope with their work regardless of their potential illnesses and other defects. We examine the connection between the organizational changes that the employees encounter and their self-assessed work ability. Self-estimated work ability is in itself an important matter, but according to the previous research it also indicates the employee's likelihood of taking sick leave or retiring early due to health reasons [5]. Secondly, we examine the connection between organizational changes and work ability separately, through the different elements affecting work ability. As we see it, work ability and inability to work are not solely about the health and motivation of the individual. According to Juhani Ilmarinen's theory, work ability consists of a) the health of the individual, b) the professional competence of the individual, c) the values, attitudes and commitment of the individual, and d) elements related to work [6]. As we see it, work ability is created by a well-balanced relationship between these elements. In this paper, we aspire to look beyond work ability into these employees' personal resources and the elements related to work. As we analyze the connection between organizational changes and work ability, and the different elements related to work ability, we pay special attention to two factors in addition to the organizational changes themselves: the employee's understanding of why the changes were made, and the opportunities employees had to be involved in the planning and implementation of these changes.

\section{Employees' understanding of changes}

In the discussion and research literature on leadership in organizational change, for the last three decades the center stage has been taken by the manager's ability to gain a shared understanding with his/her staff about the organization's need for change, its goals, and meeting these goals and following them up. Political researcher James McGregor Burns is one of the initiators of this discussion. Burns brought his view on leadership, derived from his analysis of political leaders, into the study of work organizations [7]. He challenged the idea that the relationship between the executives and the employees in a work organization must always be based on a clean-cut, mechanical and short time-horizon exchange relationship. According to him, the integral part of leadership in change was that the leaders and staff were able to share a common conception of the organization's future goals and the means to meet these goals. Burns' conception of leadership has been widely accepted, and these remarks, originally derived from the analysis of political leaders, have also been raised as the ideal of leadership in changing work organizations [8-10]. Research literature on social and health care from the last two decades also indicates that the way in which change is led is important for both the employees' work motivation and health. An especially important part of this is ensuring that employees are adequately aware of the advance planning, implementation and follow-up stages of change [11-15].

\section{Employees' opportunities to be involved in changes}

During the last few years, 'top-down' organizational changes have been giving way to the so-called employee-driven innovations [16]. In the Nordic context, employee-driven innovations can be viewed as a sort of a continuum to the movement that during the 1960s strove to democratize work, in opposition to the Tayloristic work organization. This change, 
caused by the work democratization movement, has to this day continued to produce a considerable amount of research literature on the connection between the grassroots level employees' opportunities to influence their own work and work motivation, well-being, and health [17-21]. Thus, for decades now, we have not labored under the false pretence that all creativity lies at the top of organizations and among consultants. However, over the last years, the discussion on employee-driven innovations has further expanded the employee's role of developer of his/her organization. In the social and health care industry also, the grassroots level employees have recently been challenged to innovate spheres beyond their own work processes within their respective organizations [22]. It may very well be that the large group of grassroots level employees that daily meet the clients of their organization is an extremely useful tool for developing their organization in an increasingly active way. However, until now, little attention has been paid to the expectations that are placed on employees in their new roles as active participants in the change process. In social and health care, the employee's role and authority has been traditionally clearly marked by different organizational levels and the hierarchy existing between the different professionals of the industry. Against this background, taking the "helicopter perspective", which is the pre-requisite to employee-driven innovation, may in practice be very difficult and arduous for grassroots level employees. In addition, the employees of Finnish social and health care are under a great deal of strain caused by large numbers of clients and the responsibility they feel for them [23]. It is therefore also necessary to examine whether the opportunity to be involved in the change process affects the staff's work ability in a categorically positive way.

\section{OBJECTIVE}

In this paper we focus on the risk that employees who have experienced organizational change may feel that their work ability and the different elements related to it have deteriorated, in comparison with employees whose workplaces have not undergone any organizational changes. In addition to this, we also ask whether the employees who felt that they did not understand the changes are at a higher risk of suffering from diminished work ability, or deterioration in the elements related to work ability, than those employees who felt that the changes were understandable. Thirdly, we ask whether the employees who felt that their opportunities to be involved in the change process had been poor are at a higher risk of feeling that their work ability and elements related to it have deteriorated than those employees who stated that their opportunities to be involved were good.

\section{METHODS}

\section{Study design and participants}

We employed a cross-sectional survey to order to carry out the research. We asked the respondents to identify the organizational changes that had transpired at their workplaces over the previous two years, and invited them to evaluate how well they understood these changes, as well as to tell us whether or not they had had the opportunity to be involved in the change process. In addition to this, we asked the respondents to evaluate their work ability and assess whether certain statements related to the different elements of work ability were true or false at the time of the survey.

A sample of 5000 Finnish social and health care workers was selected to take part in the study from the work registry of Statistics Finland. In early 2010, when the material was collected, the register available was from 2007. Thus, the people who entered the field during the last two years were left out of the sample, and all of the employees in the study had worked in the field of social and health care for at least two years. The method we employed was stratified random sampling. The sample chosen was based on the field of operation of the workplace and geographical 
location. In 2010, we used the pan-European classification of field of operation (NACE), which was first introduced in 2008 and divides the field of social and health care into 11 different sample sectors. These sample sectors are: the social service sector, children's day care, home care, nursing homes, supported housing, services for the disabled, the mental health and drug abuse sector, outpatient care, health centers wards, hospitals, and others. The sample for this study was collected so that even from the smallest sample section we obtained a sample of at least 200 people. We also took geographical representation into consideration when collecting the sample. The sample was chosen so that all 19 provinces of Finland were represented in proportion to their relative sizes.

The survey forms were mailed to the respondents together with a pre-paid return envelope. The response rate for the survey was $61.8 \%$, which means that a total of 3090 respondents answered the survey. Before conducting the analysis, 397 respondents who no longer worked in the field of operation during the time of the survey, but who were chosen in the register-based selection, were removed from the data. We also removed 264 respondents from the data who continued to work in the field, but had not answered the questions concerning organizational changes. Thus, 2429 respondents were accepted into the final research data. Out of these respondents, $76 \%$ worked in the public sector, $17 \%$ in private enterprises, $3 \%$ in non-profit organizations (the so-called third sector), and 3\% were self-employed. This distribution corresponds well to the real situation in the Finnish social and health care industry [24].

\section{MEASURES}

\section{Organizational change}

We asked the respondents whether any organizational changes had occurred at their workplaces within the previous two years, or if their workplaces were currently undergoing any changes related to organizational structure or operations. The answer alternatives were yes/no.

\section{Understanding and participating in changes}

For questions related to the understandability of the change and opportunities to be involved in the change process, we applied the research by Kinnunen and Lindström on the connection between structural and operational changes and the well-being of personnel [14]. We built our own battery of questions based on their questions, which were thus scientifically tested. To measure the understandability of change, we used a group of questions comprising four statements.

These statements were: a) I have received an adequate amount of information on how the changes will affect my work, b) The reasons for the change are not clear to me (in follow-up work this statement was revised to match the other statements), c) The goals of the change are clear to me, d) I have been well aware of the progress and different stages of the change process. The indicator we used to measure the opportunity to be involved in the change process comprised two statements: a) Staff have been sufficiently involved in the planning of the change, b) I have been able to influence the implementation of change at my workplace.

The different answers were given on a five-point Likert scale: $(1=$ fully agree, 2 = agree to a point, $3=$ neither agree nor disagree, 4 = disagree to a point, $5=$ fully disagree). The original six subquestions were united to form two sum variables: 'the understandability of the change' and 'the opportunity to be involved in the change'. The Cronbach's alpha coefficients measuring the internal consistency of the sum variables were 0.76 and 0.79 . Prior to the analysis, both sum variables were dichotomized by combining alternative answers 1 and 2, and alternatives [3-5] to form their own categories. 


\section{Work ability and elements of work ability}

We asked the respondents to evaluate their work ability. For the analysis of the question measuring the respondents' work ability, we utilized a work ability index developed by Finnish researchers [25]. We only used the first and most important question of the index. In the previous studies, this question had effectively predicted the outcome of the work ability index, which comprises seven subquestions [26]. The exact question posed to the respondents is as follows: Let's assume that your work ability at its best is worth 10 points. How many points would you give your current work ability? The respondents estimated their work ability on an 11-point scale ( $0=$ entirely incapable of working, to $10=$ at the height of work ability). The work ability estimations, as in the previous studies, were dichotomized by combining answer alternatives $0-7$ and alternatives 8-10 to form their own categories [27].

For the elements that have an impact on work ability, we utilized Juhani Ilmarinen's work [6]. According to his model, work ability consists of a) the health of the individual, b) the professional competence of the individual, c) the values, attitudes and motivation of the individual, and d) elements related to work.

We measured the health of the respondents via their own estimations, on a five-point Likert scale $(1=$ good, 2 = fairly good, $3=$ moderate, 4 = fairly poor, $5=$ poor). Self-evaluation of health is one of the most often used measures of health, and low self-evaluated health has been shown to be connected to several illnesses [28,29]. Similarly to the previous studies, the indicator of self-evaluated state of health was dichotomized before the analysis by combining answer alternatives 1 and 2, and alternatives 3-5 to form their own categories [30,31].

To elicit the respondents' professional competence, we asked about their ability to perform their work tasks. The respondents were asked to evaluate their capabilities on a three-point scale $(1=$ I need further training to be able to cope well with my work tasks, $2=$ My work tasks correspond well to my current abilities, $3=\mathrm{I}$ can handle more complicated work tasks than the ones assigned to me at the moment). The previous studies had shown that work tasks that are appropriately challenging; not too easy, but not too demanding either, are connected to work ability [32]. Thus, the indicator was dichotomized by combing answer alternatives 1 and 3 to form the "capabilities do not correspond with work tasks' category and alternative 2 became the 'capabilities correspond with work tasks' category.

We measured attitudes and commitment by presenting the respondents with four statements. These were: a) My work is rewarding and I work because I enjoy it, b) My current job is an essential part of my life, c) I regard my profession highly, d) I am personally committed to my current work. The respondents estimated their values, attitudes and commitment on a five-point Likert scale ( $1=$ fully agree, $2=$ agree to a point, $3=$ neither agree nor disagree, $4=$ disagree to a point, $5=$ fully disagree). The original four subquestions were combined to form one sum variable: 'attitudes and commitment'. The Cronbach's alpha coefficient measuring the internal consistency of the sum variable was 0.79 . Prior to the analysis, the sum variable was dichotomized by combining alternative answers 1 and 2, and alternatives 3-5 to form their own categories. We examined the elements related to work according to the Ilmarinen's model. He divides these elements into four subfactors: managerial work and leadership, work community and organization, work content and demands, and working conditions.

Firstly, managerial work and leadership were measured by asking the respondents to evaluate the justice of the decisions made at their workplaces. The previous studies had shown that the employees' view on how just decisionmaking is, is one of the most essential factors determining managerial work and leadership, and is associated not only with the well-being of staff, but also with the performance of the workplace in general [33,34]. For the questions 
measuring justice, we utilized the work by Mooirman [35]. The statements were as follows: a) At our workplace, decisions are made based on real information, b) At our workplace, unsuccessful decisions can be retracted or changed, c) All parties concerned are represented in decision-making, d) All decisions made at our workplace are consistent, e) Everybody has the right to state their opinion on matters that concern them, f) The effects of decisions are followed up and are communicated to the staff, g) More information on the grounds of decisions is available to those who want it. The respondents estimated the justice of decision-making at their workplace on a five-point Likert scale $(1=$ fully agree, $2=$ agree to a point, $3=$ neither agree nor disagree, 4 = disagree to a point, 5 = fully disagree). The seven original subquestions were combined to form one sum variable: 'the justice of decision-making'. The Cronbach's alpha coefficient measuring the internal consistency of the sum variable was 0.91 .

Secondly, we measured the functionality of work community through four statements: a) Our work community is flexible, b) Our work community operates efficiently, c) The co-operation between the different members of our work community works well, d) The division of labor in our work community is successful. The respondents estimated the functionality of their workplace on a five-point Likert scale $(1=$ fully agree, $2=$ agree to a point, $3=$ neither agree nor disagree, $4=$ disagree to a point, $5=$ fully disagree). The original four subquestions were combined to form one sum variable: 'functionality of work community'. The Cronbach's alpha coefficient measuring the internal consistency of the sum variable was 0.85 .

Thirdly, we measured work contents and demands by asking the respondents how often within the previous 12 months they had been bothered, worried or stressed about obscurity in their job description. The respondents gave their estimation on a five-point Likert scale ( 1 = very rarely or never, 2 = quite seldom, 3 = every now and again, 4 = quite often, 5 = very often or continuously).
Fourthly, we measured working conditions through the occurrence of time pressure. The previous studies had shown that the prevalence of time pressure often proved to be a factor that strained the staff of the social and health care industry [24]. We asked the respondents how often within the previous 12 months they had been bothered, worried or stressed over the following issues: a) Constant rush and pressure caused by work that has not been done, b) Inadequate number of staff, c) Too little time to take breaks during the work day. The respondents gave their estimation on a five-point Likert scale $(1=$ very rarely or never, $2=$ quite seldom, $3=$ every now and again, $4=$ quite often, 5 = very often or continuously). All subquestions were combined to form one sum variable: 'exposure to time pressure'. The Cronbach's alpha coefficient measuring the internal consistency of the sum variable was 0.84 . Prior to the analysis, all three sum variables measuring work-related elements and the question measuring the stress factor related to obscurity of job description were dichotomized by combining answer alternatives 1 and 2, and alternatives 3-5 to form their own categories.

\section{Background characteristics}

We mapped our respondents' background characteristics by asking them about their gender, age, marital status, professional education and whether or not they worked in a managerial position.

\section{Statistical Analysis}

We formed logistical regression models of the eight previously described response variables defining self-evaluated work ability and the different elements related to it. We divided our regression models into three groups according to their explanatory variables.

In the first group, we examined organizational changes. In this case, the control group for the respondents who reported having undergone changes was formed by the respondents whose workplaces had encountered no 
changes. In the second group, we studied the understandability of the changes reported by our respondents. In this case, the control group for the respondents who felt that they did not understand the changes was formed by those respondents who felt the changes were understandable. In the third group, we studied the respondents' opportunities to be involved in the change process, and here the control group for the respondents who felt their opportunities to participate had been poor were those respondents who felt that they had good opportunities to be involved in the change process.

Thus, we formed 24 logistical regression models to study the eight response variables in three different groups. For our method of analysis, we deployed logistical regression analysis, because it enabled us to simultaneously study the dependence of the dichotomized response variables on more than one explanatory variable. Logistical regression analysis does not explain the realized distributions, but rather aims at predicting probabilities. In this study, we used the analysis method to study the extent of the risk that the studied groups (that were formed based on exposure) belonged to certain other groups (formed based on response) when the other related factors were adjusted for. Values above one denote that the risk is higher than among the control group, and values below one indicate a risk that is lower than among the control group. In this paper, we adjusted for gender, age, marital status, professional education, and managerial position in each logistical regression model. A total of $0-1.5 \%$ of the answers per question was missing.

\section{RESULTS}

Out of all the 2429 respondents, $68.3 \%$, that is 1659 respondents, had encountered organizational changes within the previous two years. Table 1 presents the respondents' background characteristics in relation to the organizational changes that had transpired at their workplaces. There was no statistically significant difference between any of the groups in relation to any of the background variables we examined.

Table 2 demonstrates the risk that employees who have encountered organizational change may feel that their work ability and the different elements related to it have deteriorated in comparison to the respondents whose organizations have undergone no changes. This table shows that the respondents who had experienced organizational changes within the previous two years were almost one and a half times more likely to feel that their work ability was diminished. There is, however, no significant difference in terms of self-evaluated state of health. The risk that the respondents' abilities do not correspond with their work tasks was 1.27 times higher among the respondents who had experienced changes, as was the risk of them having negative attitudes and lack of commitment that affect work ability. In comparison to the respondents who had not experienced changes, the respondents who had been touched by changes were more likely to label work-related issues negatively. The risk that an employee felt that: (1) the decisions made had been unjust was 1.76 times higher; (2) the work community functioned inefficiently - 1.5 times higher; (3) job descriptions were obscure and caused strain - 1.42 higher, and (4) hurry caused stress more than twice as high.

Out of 1659 respondents who had experienced changes, $81.9 \%$, or 1359 respondents, stated that they did not understand the change. As much as $90 \%$, i.e. 1493 respondents, estimated that their opportunities to be involved in the change process were lacking. The respondents' background characteristics in relation to how well they understood the changes and how highly they ranked their opportunities to be involved in the changes are presented in Table 3. The respondents who felt they did not understand the changes and the respondents who felt that their opportunities to be involved in the change process had been poor were more often not in a managerial position, had 
Table 1. Respondents according to their background variables in relation to the organizational changes they had experienced over the previous two years

\begin{tabular}{lccc}
\hline \multirow{2}{*}{ Response variables } & \multicolumn{2}{c}{ Organizational change over the previous two years } \\
\cline { 2 - 4 } Gender & all & no & yes \\
male & $204(8.5)$ & $65(8.4)$ & $139(8.4)$ \\
female & $2225(91.6)$ & $705(91.6)$ & $1520(91.6)$ \\
Age (years) & & & \\
$\quad<45$ & $929(38.2)$ & $307(39.9)$ & $622(37.5)$ \\
$45-54$ & $841(34.6)$ & $251(32.6)$ & $590(35.6)$ \\
$>55$ & $659(27.1)$ & $212(27.5)$ & $447(26.9)$ \\
Marital status & & & \\
single & $213(8.8)$ & $68(8.8)$ & $145(8.7)$ \\
cohabitating or married & $1887(77.7)$ & $605(78.6)$ & $1282(77.3)$ \\
divorced, separated or widowed & $328(13.5)$ & $97(12.6)$ & $231(13.9)$ \\
Professional education & & & $125(7.6)$. \\
no education or vocational course & $201(8.3)$ & $76(9.9)$. & $1029(62.3)$ \\
vocational diploma or other intermediate degree & $1492(61.7)$ & $463(60.5)$ & $498(30.1)$ \\
higher vocational diploma or university degree & $724(30.0)$ & $226(29.5)$ & \\
Managerial position & & & $1504(91.9)$ \\
no & $2204(92.1)$ & $700(92.6)$ & $133(8.1)$ \\
yes & $189(7.9)$ & $56(7.4)$ & \\
\hline
\end{tabular}

Table 2. Risk of respondents who had experienced organizational changes having decreased self-evaluated work ability and elements related to work ability

Response variables

Respondents who had undergone changes

(OR)

Decreased self-evaluated work ability

$1.49^{* * *}$

Self-evaluated health average or poor

1.18

Ability does not correspond to work tasks

$1.27 * *$

Attitudes and commitment do not promote work ability

$1.27^{*}$

Factors related to work

decisions made at workplace are unjust

$1.76^{* * *}$

functionality of work community deteriorated

$1.54^{* * *}$

obscure job description strains

$1.42^{* * *}$

time pressure causes stress

$2.04 * * *$

Gender, age, marital status, professional education and managerial position were adjusted for in each logistic regression model.

$\mathrm{OR}$ - adds ratio.

$\mathrm{p}^{*}<0.05,{ }^{* *}<0.01,{ }^{* * *}<0.001$. 
been educated in a vocational institute or in another intermediate school, and were women.

Table 4 presents the risk that the respondents who stated they did not understand the changes might also feel that their work ability and the different elements affecting it had deteriorated, in comparison to those respondents who felt that the changes they had encountered were understandable. The table shows that the respondents who felt that the changes were not understandable were almost twice as likely to feel that their work ability was poor in comparison to the respondents who stated that they understood the changes. The risk was more than 1.5 times higher as regards self-evaluated health. There was no significant difference between the two groups regarding the risk that the employee's ability does not correspond to his/her work tasks. However, the group who did not understand the changes was almost twice as likely to have a negative attitude and lack of commitment that affects work ability. The risk that the respondents felt that: (1) the decisions made had been unjust was more than four times as high; (2) the work community functioned inefficiently and job descriptions were obscure and caused strain more than twice as high; and (3) hurry caused stress - almost twice as high.

Table 4 also presents the risk that those respondents who felt that their opportunities to be involved had been poor would also feel that their work ability and its different elements had deteriorated, in comparison to the respondents who felt that their opportunities to be involved in the change process had been good. The table shows that those

Table 3. Respondents according to their background variables in relation to understandability of organizational changes and opportunities to be involved in them

\begin{tabular}{lcccc}
\hline \multirow{2}{*}{ Response variables } & \multicolumn{2}{c}{ Change understandable } & \multicolumn{2}{c}{ Good opportunities to be involved } \\
\cline { 2 - 5 } & yes & no & yes & no \\
\hline Gender & & $*$ & & $* * *$ \\
$\quad$ male & $35(11.6)$ & $107(7.9)$ & $30(17.9)$ & $112(7.5)$ \\
$\quad$ female & $265(88.4)$ & $1252(92.1)$ & $136(82.1)$ & $1,381(92.5)$ \\
Age (years) & & & & \\
$\quad<45$ & $113(37.8)$ & $514(37.8)$ & $56(34)$ & $575(38.5)$ \\
$45-54$ & $109(36.4)$ & $478(35.2)$ & $64(38.3)$ & $524(35.1)$ \\
$>55$ & $78(25.8)$ & $367(27.0)$ & $46(27.7)$ & $394(26.4)$ \\
Marital status & & & & \\
$\quad$ single & $23(7.8)$ & $121(8.9)$ & $12(7.4)$ & $131(8.8)$. \\
$\quad$ cohabitating or married & $234(77.9)$ & $1,051(77.4)$ & $123(74.1)$ & $1,161(77.8)$ \\
$\quad$ divorced, separated or widowed & $43(14.3)$ & $186(13.7)$ & $31(18.5)$ & $200(13.4)$ \\
Professional education & & $* *$ & & $* * *$ \\
no education or vocational course & $28(9.2)$ & $99(7.3)$ & $13(8.1)$ & $113(7.6)$ \\
$\quad$ vocational diploma or other intermediate degree & $158(52.9)$ & $867(64.1)$ & $80(48.4)$ & $946(63.6)$ \\
higher vocational diploma or university degree & $113(37.9)$ & $87(28.6)$. & $72(43.5)$ & $428(28.8)$ \\
Managerial position & & $* * *$ & & $* * *$ \\
no & $246(83.2)$ & $1,258(93.8)$ & $126(76.7)$ & $1,376(93.4)$ \\
yes & $50(16.8)$ & $83(6.2)$ & $38(23.3)$ & $97(6.6)$ \\
\hline
\end{tabular}

$\mathrm{p}^{*}<0.05,{ }^{* *}<0.01,{ }^{* * *}<0.001$. 
Table 4. Risk of respondents who stated that changes were not understandable or who had had poor opportunities to be involved in them having decreased self-evaluated work ability and elements related to work ability.

\begin{tabular}{lcc}
\hline \multicolumn{1}{c}{ Response variables } & $\begin{array}{c}\text { Change not understandable } \\
(\mathrm{OR})\end{array}$ & $\begin{array}{c}\text { Opportunity to be involved poor } \\
(\mathrm{OR})\end{array}$ \\
\hline Deceased self-evaluated work ability & $1.99^{* * *}$ & $2.16^{* * *}$ \\
Self-evaluated health average or poor & $1.58^{* *}$ & 1.35 \\
Ability does not correspond to work tasks & 1.13 & 0.90 \\
Attitudes and commitment do not promote work ability & $1.92^{* * *}$ & $2.07^{* *}$ \\
Factors related to work & & $4.88^{* * *}$ \\
decisions made at the workplace are unjust & $4.25^{* * *}$ & $2.03^{* * *}$ \\
functionality of work community deteriorated & $2.35^{* * *}$ & $1.56^{*}$ \\
obscure job description strains & $2.19^{* * *}$ & $2.26^{* * *}$ \\
time pressure causes stress & $1.89^{* * *}$ & \\
\hline
\end{tabular}

Gender, age, marital status, professional education and managerial position were adjusted for in each logistic regression model.

$\mathrm{OR}$ - odds ratio.

$\mathrm{p}^{*}<0.05, * *<0.01, * * * 0.001$.

respondents who felt their opportunities to be involved in the changes had been poor were more than twice as likely to feel that their work ability was impaired in comparison to those respondents who stated that their opportunities to be involved had been good. There was no significant difference between these two groups as regards self-evaluated state of health, nor in whether the employees' abilities were in accordance with their work tasks. Instead, the group who felt that their opportunities to be involved in the changes had been poor was almost twice as likely to present a negative attitude and lack of commitment. The risk that the respondents felt that: (1) the decisions made had been unjust was almost five times as high; (2) the work community functioned inefficiently and hurry caused strain - more than twice as high; and (3) obscure job descriptions caused strain -1.5 times as high.

\section{DISCUSSION}

This study showed that the risk that employees who had experienced organizational changes may feel that their work ability had decreased was almost 1.5 times higher than that of those employees whose workplaces had undergone no changes. This result concurs with a British cohort-study that investigated the connection between privatization change and the public sector employees' work disability [36]. This organizational change understandably corresponds to defects in work ability due to e.g. the transition of the labor market position of employees. Work in British public administration was traditionally viewed as a life-long career, and thus the change implemented at the beginning of the 1990s, i.e. to operate according to operation logics adopted from the private sector, not only possibly altered the demands set for such work, but also posed a possible threat to the work ability of employees, as their jobs shifted from "secure to insecure". In this study, in early 2010, we asked professionals working in the Finnish social and health care industry to identify all the organizational changes that had occurred at their workplaces over the previous two years. Our sample, which embraced all of the 19 Finnish provinces, as well as the different operational sectors of social and health care, covers various organizational changes.

Thus, the higher risk that employees who hae encountered changes may have diminished work ability cannot be 
explained by only one specific change and its side-effects. Our findings inevitably challenge us to follow-up with a new question: is decreased work ability connected solely to the changes as such, or is there something particular about the organizational changes of Finnish social and health care that penetrates through the whole industry and weakens the work ability of its employees? The contemporary diagnoses of Finnish work life offer one explanation: The organizational changes of today invariably have to do with the intention to intensify labor [37,38]. Based on this study, we feel confident in stating that the connection between organizational changes and work ability go beyond the change as such; the way in which the changes are implemented play an important role. The employees who did not feel they comprehended the changes were, in comparison to those who felt they understood the changes, almost twice as likely to feel that their work ability was impaired. The risk that employees who felt that their opportunities to be involved in the change process had been poor may feel that their work ability had decreased was more than twice as high as that of the employees who felt that they had been allowed to take part in the changes.

We also looked beyond the self-evaluated work ability of the employees, to the resources of the individuals. In accordance with Ilmarinen's model, we paid attention to the self-evaluated state of health, the correlation between the abilities and work tasks, and the attitudes and commitment of employees. There was no statistical significance which could suggest that organizational changes increased the risk of weakened self-evaluated state of health. Although this result differs from the previous studies, it is not surprising [2-4]. In this study, we aimed at reaching a wide range of organizational changes, whereas the previously mentioned prior analyses were based on specific, crisesrelated or otherwise extremely radical changes. Because the health of employees is connected to elements related to work in only a limited sense, we have to assume that the changes related to work have to be major in order to affect the health of employees. Our study, however, showed that the employees who had encountered organizational changes were at a higher risk of feeling that their abilities did not correspond to their current work tasks. What is interesting in this, is that feeling that the changes were not understandable, or that the opportunities to be involved in the change process had been poor, did not increase the risk. Those employees who had encountered organizational changes were also at a higher risk of displaying negative attitudes and lack of commitment to their work. In this respect, feeling that the changes were not understandable and that opportunities to be involved in the changes had been poor increased the risk.

As well as evaluating the resources of individuals, Ilmarinen's model guided us to look beyond work ability at the elements related to work. We, therefore, examined the connections between organizational changes and the unjustness of decisions that had been made at the workplace, the dysfunctionality of the work community, the strain caused by obscure job description, and stress caused by constant time pressure. The employees who had been faced with organizational changes during the previous two years were more likely to feel that all of these elements related to their work were negative than those employees who had experienced no changes. Furthermore, among those employees who stated that they did not understand the changes, the risk of feeling that the elements were negative was higher than among those who understood the changes, as was the case among the employees who felt that their opportunities to be involved in the change process had been poor, in comparison to those who stated that their opportunities had been good. All in all, it appears that the risk of employees who had been touched by organizational changes having weakened work ability is better explained in this study by the elements related to work than the collapse of employees' health and other personal resources. In fact, it might even be that the risk of employees who had experienced organizational changes 
suffering from weakened work ability was no higher than this study showed because the employees were, thanks to their good state of health, able to maintain their work ability regardless of the stress factors related to their work. In this case, the risk that employees faced with organizational changes might suffer from poor health may, in a longer period of observation, manifest itself very differently.

When interpreting the results of this study, it is important to highlight certain characteristics. Firstly, the data we used in this study was collected using a cross-sectional method, in which data concerning both the exposure (organizational change, understandability of the changes, opportunities to be involved in the change process) and response (self-evaluated work ability and its elements) were collected simultaneously. Thus, one has to be very cautious when drawing conclusions about cause-and-effect relationships between exposure and response. After all, we have no knowledge of the original status of the employees' self-evaluated work ability, or the elements affecting it. In other words, we have no knowledge of the situation prior to the organizational changes. In this paper we studied risks: the extent of the risk of the studied groups (formed based on exposure) belonging to certain other groups (formed based on response) when other related factors were adjusted for.

Secondly, it is important to bear in mind that in this study the respondents were asked to identify the organizational changes that had occurred at their workplaces during the previous two years, but were not asked to specify the point of time of the changes more accurately. As previously mentioned, it is possible that the temporal distance between the change and the survey might play a considerable role, especially in self-evaluated state of health.

Thirdly, the sum variable measuring the respondents' opportunities to be involved in the changes consisted of two statements that measured the involvement from a positive angle. In hindsight, it might have been more productive to also measure the involvement with less positive phrasing.
The additional statements could have been formulated along the lines of: 'management required me to be involved with the planning/implementation of the change'. This kind of formulation might have caught on better than the indicator we used with those respondents who felt their opportunities to be involved were good, but who from the beginning did not want to be involved.

Fourthly, when interpreting the results, the historical point in time at which the study was conducted has to be considered. The economic recession that started spreading from the international finance markets in 2008 had, by the beginning of 2010 when the study was conducted, started to have serious effects on the Finnish service sector and public finances.

In this context, it is possible to deliberate the possible effects of economic recession on the organizational changes in the social and health care industry via the previous economic recession that had taken place in Finland in the 1990s. In contrast to what was publicly claimed, the financial cutbacks during the 1990s economic recession in Finland were not conducted evenly in all operational sectors. Instead, the cuts were especially severe on the care of the elderly and the sectors of mental health and substance abuse; heavy institutional services were shut down as planned, but the substitutive outpatient services did not materialize, due to the recession [39]. However, despite the cutbacks, the quality of social and health care services did not radically decrease in any sector, as the personnel of the industry ensured that the services were adequate by making personal compromises [40]. Thus, the cutbacks did not fully project themselves on the services provided to civic clients. Instead, they took their toll on the employees. Where the cuts were the toughest, the employee's risk of cardiac-related death increased as dramatically as by $50 \%$ [1]. Thus, during the previous economic recession in Finland, the employees working in the social and health care industry had maintained an adequate level of services for those client groups who had been the weakest 
to survive the cuts, and they did this at the cost of their own health. It is also possible that in this study conducted during the economic recession of the 2000s, some of the risk of employees who had experienced organizational changes feeling that their work ability and its elements had deteriorated is explained by the co-existence of organizational changes due to the recession, e.g. the personnel cuts that were part of the changes.

\section{CONCLUSIONS}

Our findings suggest that organizational changes in social and health care, especially when poorly conducted, may result in costs to employees, employers and society at large. When implementing organizational changes, it is vital to ensure that the employees understand why the changes are being made, and that they are given the opportunity to take part in the planning and implementation of these changes.

\section{ACKNOWLEDGEMENTS}

The authors would like to thank Marjukka Laine for data collection and project management and Antti Vallaskangas for his valuable comments regarding the analysis.

\section{REFERENCES}

1. Vahtera J, Kivimäki M, Pentti J. Effect of organizational downsizing on health of employees. Lancet 1997;350:1124-8.

2. Ferrie JE, Shipley MJ, Marmor MG, Stansfeld S, Smith GD. The health effects of major organizational change and job insecurity. Soc Sci Med 1998;46:243-54.

3. Hansson A-S, Vingård E, Arnetz B, Anderzen I. Organizational change, health, and sick leave among health care employees: A longitudinal study measuring stress markers, individual, and work site factors. Work Stress 2008;22:69-80.

4. Schweiger DM, Ivancevich JM. Human resources: the forgotten factor in mergers and acquisitions. Pers Admin 1985;30:47-61.
5. Tuomi K, Wägar G, Eskelinen L, Järvinen E, Huuhtanen P. Health, work ability and working conditions in municipal occupations. In: Ilmarinen J, editor. Work, health and retirement age in municipal sector. Helsinki: Finnish Institute of Occupational Health series 1985;3:95-132 [in Finnish].

6. Ilmarinen J. Work ability - a comprehensive concept for occupational health research and prevention. Scand J Work Environ Health 2009;35:1-5.

7. Burns JM. Leadership. New York: Harper \& Row; 1978.

8. Bass B. Leadership and performance beyond expectations. New York: Free Press; 1985.

9. Bryman A. Charisma and Leadership in organizations. London: Sage Publications; 1992.

10. Northouse PG. Leadership - Theory and Practice. London: Sage Publications 2004.

11. Schweiger DM, DeNisi AS. Communication with employees following a merger: A longitudinal field experiment. Acad Manag J1991;34:110-35.

12. Sverke M, Hellgren J., Öhrning J. Organizational restructuring and health care work: A quasi-experimental study. In: LeBlank PM, Peters MCW, Bussing A, Schaufeli WB, editors. Organizational psychology and health care. Munchen and Mering: Rainer Hampp Verlag; 1999. p. 15-32.

13. Roald J., Edgren L. Employee experience of structural change in two Norwegian hospitals. Int J Health Plan Manag 2001;16:311-24.

14. Kinnunen J, Lindström K. Effects of organizational changes in health care. Analysing management and welfare of personnel in Hospital District of Helsinki and Uusimaa. Kuopio: Kopiojyvä; 2005 [in Finnish].

15. Laschinger HKS, Finegan J, Wilk P. Situational and Dispositional Influences on Nurses' Workplace Wellbeing: The Role of Empowering Unit Leadership. Nurs Res 2011;60:124-31.

16. Kesting P, Ulhoi JP. Employee-driven innovation: extending the license to foster innovation. Manag Dec 2010;48:65-84.

17. Adler P. Democratic Taylorism: The Toyota production system at NUMMI. In Babson S, editor. Lean work: Empowerment 
and exploitation in the global auto industry. Detroit: Wayne State University Press; 1995. p. 207-19.

18. MacDuffie JP. Worker's roles in lean production: The implications for worker representation. In Babson S, editor. Lean work: Empowerment and exploitation in the global auto industry. Detroit: Wayne State University Press; 1995. p. 54-69.

19. Anderzen I, Arnetz BB. The Impact of a Prospective SurveyBased Workplace Intervention Program on Employee Health, Biologic Stress Markers, and Organizational Productivity. J Occup Environ Med 2005;47:671-82.

20. Arnetz BB. Subjective indicators as a gauge for improving organizational well-being. An attempt to apply the cognitive activation theory to organizations. Psychoneuroendocrinology 2005;30:1022-6.

21. Svensen E, Neset G, Eriksen HR. Factors associated with a positive attitude towards change among employees during the early phase of a downsizing process. Scand J Psychol 2007;48:153-9.

22. Hasu M, Saari E, Mattelmäki T. Bringing the employee back in: Integrating user-driven and Employee-driven innovation in public sector. In: Sundbo J, Toivonen M, editors. User based innovation in services. Cheltenham UK: Edvard Elgar; 2011. p. 251-81.

23. Kokkinen L. Underpaid, overworked and still happy. The paradox of nursing labor job satisfaction. J Healthcare Leadership. In press 2012.

24. Ailasmaa R. Workforce in health and welfare services [cited 2011 Dec 18]. Available from URL: http://www.stakes.fi/ tilastot/tilastotiedotteet/2011/Tr13_11.pdf [in Finnish].

25. Tuomi K, Ilmarinen J, Jahkola A, Katajarinne L, Tulkki A. Work Ability Index. Helsinki: Institute of Occupational Health; 1994.

26. Ilmarinen J, Tuomi K. Past, present and future of work ability. In: Ilmarinen J, Lehtinen S, editors. Past, Present and Future of Work Ability. People and Work, Research Reports 65. Helsinki: Finnish Institute of Occupational Health; 2004. p. 1-25.
27. Pensola T, Järvikoski A, Järvisalo J. Unemployment and Work Ability. In: Gould R, Ilmarinen J, Järvisalo J, Koskinen S, editors. Dimensions of Work Ability. Helsinki: Finnish Centre for Pensions; 2008. p. 123-30.

28. Idler EL, Benyamini Y. Self-rated health and mortality: a review of twenty-seven community studies. J Health Soc Behav 1997;38:21-37.

29. Kivimäki M, Head J, Ferrie JE, Shipley MJ, Vahtera J, Marmot MG. Sickness absence as a global measure of health: Evidence from mortality in the Whitehall 2 prospective cohort study. Brit Med J 2003;327:364.

30. Idler EL, Russell LB, Davis D. Survival, Functional limitations, and self-rated health in the NHANES 1 epimediologic follow-up study, 1992. First National Health and Nutrition Examination Survey. Am J Epidemiol 2000;152:874-83.

31. Kivimäki M, Vahtera J, Elovainio M, Virtanen M, Siegrist J. Effort-reward imbalance, procedural injustice and relational injustice as psychosocial predictors of health: Complementary or redundant models? Occup Environ Med 2007;64:659-65.

32. Tuomi K, Vanhala S, Nykyri E, Janhonen M. Organizational practices, work demands and the well-being of employees: a follow-up study in the metal industry and retail trade. Occup Med 2004;54:115-21.

33. Kivimäki M, Ferrie J, Head J, Shipley M, Vahtera J, Marmot M. Organizational justice and change in justice as predictors of employee health: The Whitehall 2 study. J Epidemiol Commun Health 2004;58:931-7.

34. Simon SK, Lam J, SchauBroek SA. Relationship between Organizational Justice and Employee Work Outcomes: A CrossNational Study. J Organiz Behav 2002;23:1-18.

35. Moorman RH. The Relationship between organizational justice and organizational citizenship behaviors: Do fairness perceptions influence employee citizenship? J Appl Psychol 1991;76:845-55.

36. Virtanen M, Kivimäki M, Singh-Manoux A, Gimeno D, Shipley MJ, Vahtera J, et al. Work disability following major 
organizational change; the Whitehall 2 study. J Epidemiol Commun Health 2010;64:461-4.

37. Siltala J. A Short History of the Decline of Working Life. Helsinki: Otava; 2004 [in Finnish].

38. Julkunen R. Paradoxes of New Work. Tampere: Vastapaino; 2008 [in Finnish].
39. Lehto J, Blomster P. Recession in the 1990s and its policy influence on social and health care services. Yhteiskuntapolitiikka 1999;64:207-21 [in Finnish].

40. Kiander J. Lessons from the crisis: causes and consequences of the 1990s economic recession in Finland. Helsinki: Valtion taloudellinen tutkimuskeskus; 2001 [in Finnish].

This work is available in Open Access model and licensed under a Creative Commons Attribution-NonCommercial 3.0 Poland License - http://creativecommons.org/ licenses/by-nc/3.0/pl/deed.en. 